\title{
Decitabine combined with medium-dose cytarabine in the treatment of DEK/CAN-positive acute myeloid leukemia: a case report
}

\author{
Xueya Zhang ${ }^{1}$, Xuezhi Zhang ${ }^{2}$ \\ ${ }^{1}$ Department of Hematology, The Second Affiliated Hospital of Fujian Medical University, Quanzhou, China; ${ }^{2}$ Department of Neurosurgery, The \\ First Affiliated Hospital of Nanchang University, Nanchang, China \\ Correspondence to: Xueya Zhang, MD. Department of Hematology, The Second Affiliated Hospital of Fujian Medical University, 34 Zhongshan \\ North Road, Quanzhou, China. Email: jakey3456@sina.com.
}

\begin{abstract}
Acute myeloid leukemia (AML) is a malignant clonal hematopoietic stem cell disease. Although there are many therapeutic options, it is still an incurable hematological malignancy. Moreover, the prognosis of AML is closely related to its cytogenetics and molecular biology. The DEK/CAN fusion gene formed by $\mathrm{t}(6 ; 9)(\mathrm{p} 23 ; \mathrm{q} 34)$ occurs with an incidence of $1-5 \%$ in adult patients with AML usually indicates a poor prognosis. Hematopoietic stem cell transplantation can prolong the disease-free survival rate of patients with AML positive for DEK/CAN fusion gene, and the development of new drugs is still one of the hotspots of clinical research. Herein, we reported the first case with DEK/CAN-positive AML who achieved complete remission of molecular biology via decitabine combined with a medium-dose cytarabine regimen. The patient has received three courses of intensive treatment with decitabine combined with mediumdose cytarabine regimen and maintain complete remission of molecular biology for up to 11 months. We hypothesized that the combination of decitabine and medium-dose cytarabine play an important role in targeting DEK/CAN and it should be verified by the accumulation of clinical cases and basic experiments in the future.
\end{abstract}

Keywords: Acute myeloid leukemia (AML); DEK/CAN fusion; decitabine; cytarabine; case report

Submitted Oct 15, 2019. Accepted for publication Feb 10, 2020.

doi: 10.21037/apm-19-379

View this article at: http://dx.doi.org/10.21037/apm-19-379

\section{Introduction}

Acute myeloid leukemia (AML) is a malignant clonal hematopoietic stem cell disease. Although there are many therapeutic options, it is still an incurable hematological malignancy (1). At the same time, the prognosis of AML is closely related to its cytogenetics and molecular biology. For example, the AML1/ETO, CEBF/MYH11 resulted from $t$ $(8 ; 21)$ and inv16 indicate a good prognosis (2). However, the DEK/CAN fusion gene formed by $\mathrm{t}(6 ; 9)(\mathrm{p} 23 ; \mathrm{q} 34)$ occurs with an incidence of $1-5 \%$ in adult patients with AML usually indicates a poor prognosis (3). Hematopoietic stem cell transplantation can prolong the disease-free survival rate of patients with AML positive for DEK/CAN fusion gene, and the development of new drugs is still one of the hotspots of clinical research $(4,5)$. Herein, we reported the first case with DEK/CAN-positive AML who achieved complete remission of molecular biology via decitabine combined with a medium-dose cytarabine regimen.

We present the following case in accordance with the CARE Reporting Checklist (available at http://dx.doi. org/10.21037/apm-19-379).

\section{Case presentation}

A 40-year-old female was admitted to our hospital on December 18, 2018 due to gingival swelling and pain for 2 weeks. She was previously healthy and had no medical, family, and psychosocial history including relevant genetic disease. The physical 


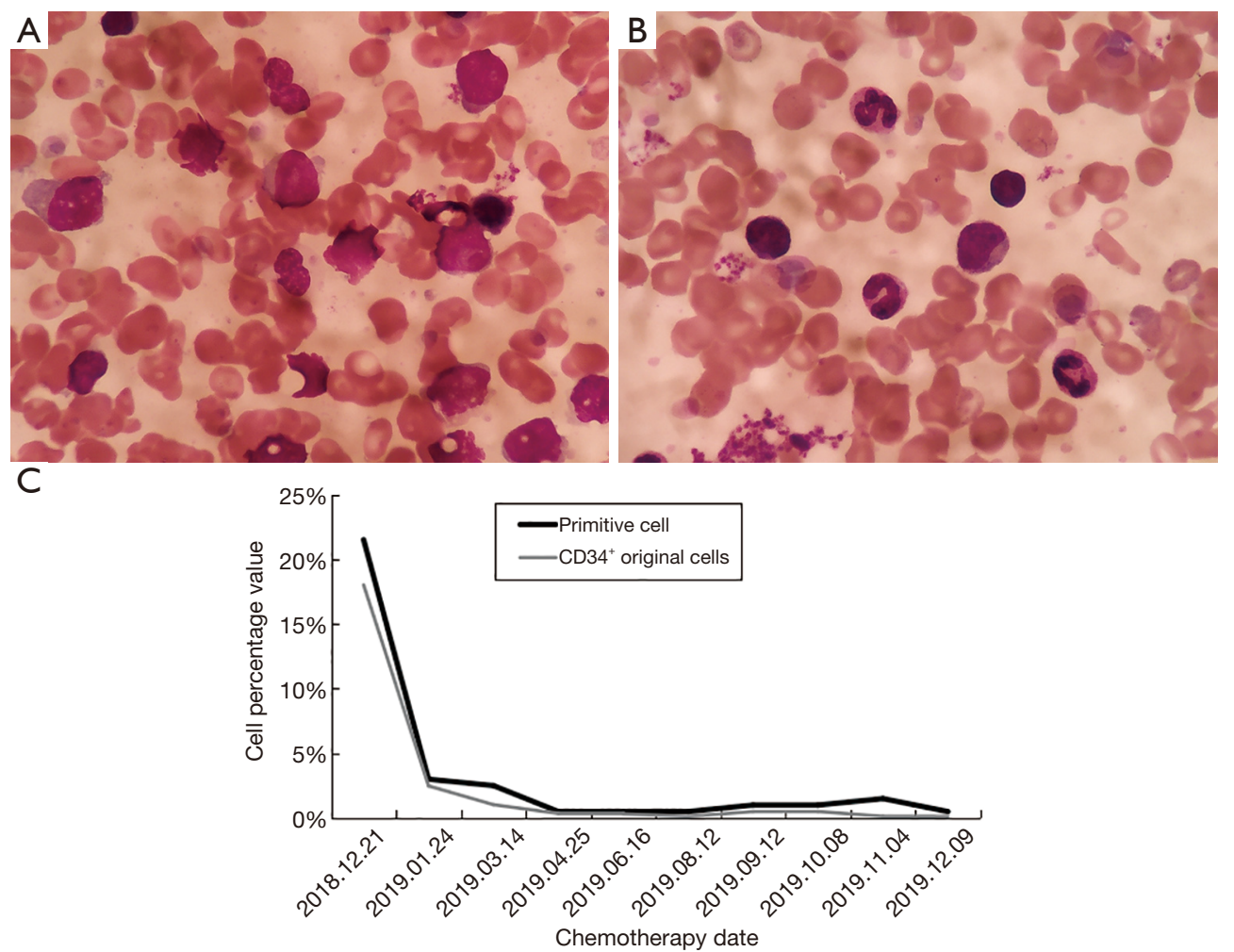

Figure 1 Changes of bone marrow morphology (by Wright's staining) and blasts ratio before and after chemotherapy. (A) Bone marrow morphology before chemotherapy $(\times 1,000)$. (B) Bone marrow morphology after chemotherapy with decitabine combined with IA regimen $(\times 1,000)$. (C) The percentage of number of primitive cells and CD34 positive cells before and after the entire treatment cycle.

examination found the liver, spleen and lymph nodes were not enlarged. The complete blood count showed WBC $2.5 \times 10^{9} / \mathrm{L}$, NE $0.8 \times 10^{9} / \mathrm{L}$, HGB $121 \mathrm{~g} / \mathrm{L}$ and PLT $251 \times 10^{9} / \mathrm{L}$. The myelogram showed obviously active proliferation of the bone marrow and abnormal development of granulocytes, the proportion of primordial granulocytes was $21.5 \%$ and peroxidase (POX) positive rate was $61 \%$ (Figure $1 A$ ). These results indicated AML-2a with morphological abnormalities of granules. Immunophenotyping of bone marrow cells showed that $15 \%$ nuclear cells were in the original region, mainly expressing HLA-DR, CD13, CD33, CD34, CD38, CD117 and CD123. DEK/CAN fusion gene was detected by multiple nested RT-PCR. Karyotype analysis of cell chromosomes revealed 46,XX. 15 AML-related genes including FLT3-ITD, dupMLL, IDH1, IDH2, NPM1, c-KIT, NRAS, CEBPA, DNMT3A, PHF6, TET2, ASXL1, RUNX1, TP53 and WT1 were all negative by high-throughput sequencing. The patient was diagnosed as AML-2a with morphological abnormalities of granules and positive DEK/CAN fusion gene according to the World Health Organization (WHO) diagnostic classification criteria (6). The chemotherapy regimen with decitabine $25 \mathrm{mg} / \mathrm{d} \mathrm{d} 1-\mathrm{d} 5$, combined with idarubicin $20 \mathrm{mg} / \mathrm{d} \mathrm{d} 6-\mathrm{d} 8$ and cytarabine $100 \mathrm{mg} / \mathrm{m}^{2} / \mathrm{d}, \mathrm{d} 6-\mathrm{d} 9$ was taken for one course and then reexamined the myelogram after chemotherapy. Minimal residual disease (MRD) suggested 3\% primordial granulocytes and DEK/CAN fusion gene was still detected by multiple nested RT-PCR. Decitabine $25 \mathrm{mg} / \mathrm{d}, \mathrm{d} 1-\mathrm{d} 5$ combined with moderatedose cytarabine $1.5 \mathrm{~g} \mathrm{q} 12 \mathrm{~h} \mathrm{~d} 6-\mathrm{d} 8$ regimen was given at February 2, 2019. Blood routine showed WBC $5.5 \times 10^{9} / \mathrm{L}$, NE $3.2 \times 10^{9} / \mathrm{L}$, HGB $102 \mathrm{~g} / \mathrm{L}$ and PLT $330 \times 10^{9} / \mathrm{L}$. A review of the bone marrow prompted complete remission (Figure 1B). DEK/ CAN fusion gene was negative for qualitative and quantitative detection. MRD were also negative. Intrathecal injection was used during the treatment to prevent central nervous system leukemia. After chemotherapy, the patient developed fever and myelosuppression. After anti infection and hemopoietic cytokine use and blood product infusion treatment, the symptoms were relieved, and no other serious adverse reactions such as liver and kidney function damage and cardiotoxicity occurred. Currently, the patient have received three courses of intensive treatment 
Table 1 Treatment characteristics of DEK/CAN positive AML patient

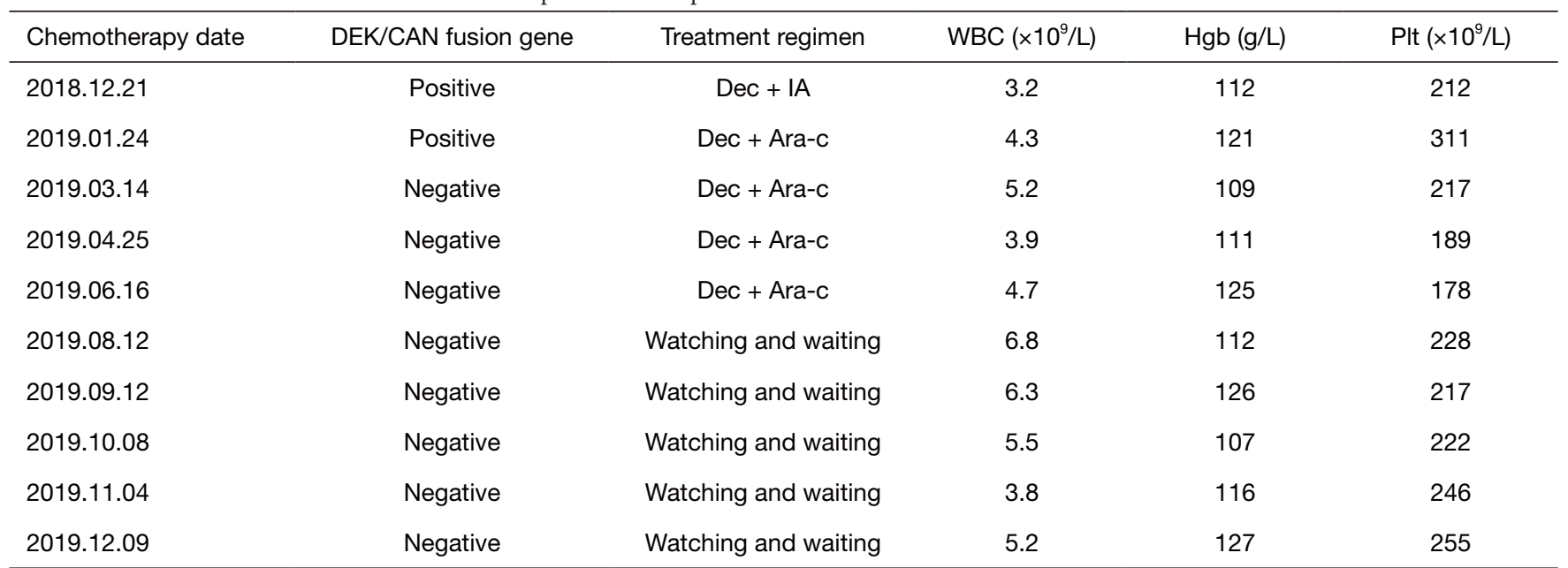

AML, acute myeloid leukemia; WBC, white blood cell; Hgb, hemoglobin; Plt, platelet; Dec, decitabine; IA, idarubicin + cytarabine; Ara-c, cytarabine.

with decitabine combined with medium-dose cytarabine regimen and maintain complete remission of molecular biology for up to 11 months (Figure 1C, Table 1).

Ethical approval was obtained from the Ethics Committee of the Second Affiliated Hospital, Fujian Medical University, China, in accordance with the ethical guidelines of the 1975 Declaration of Helsinki (committee's reference number: 2017-388). Written informed consent was obtained from the patient for publication of this manuscript and any accompanying images.

\section{Discussion}

Decetabine, a demethylase inhibitor, has been safely and effectively used in the treatment of myelodysplastic syndrome (MDS) and AML, especially in high-risk and elderly patients (7). In our case, the bone marrow image showed $21.5 \%$ primordial granulocytes and abnormal granulocyte morphology. Although t $(6 ; 9)(\mathrm{p} 23 ; \mathrm{q} 34)$ was not detected by routine chromosome analysis, combined with the results of molecular biology and immunophenotyping by flow cytometry, the diagnosis was in accordance with DEK/CAN-positive AML-M2a with granulocyte dysplasia hematopoiesis according to WHO 2016 diagnostic criteria (6). Although the patient is healthy in the past, the possibility of MDS in the pre-onset period cannot be completely ruled out.

DEK/CAN fusion gene is common in AML-M2 of FAB typing, and also in MDS. The 5 -year survival rate of children with AML is less than $30 \%$ while that of adults with AML is less than $10 \%$, suggesting that patients with DEK/CAN-positive AML have an unfavorable prognosis (3-5). Early hematopoietic stem cell transplantation can improve the prognosis. Therefore, the DEK/CAN-positive AML was listed separately in the 2016 WHO classification of myeloid tumors. The mutation rate of FLT3/ITD in DEK/CAN-positive AML patients is as high as $70 \%(8,9)$. However, previous studies have shown that FLT3/ITD mutation was not an independent adverse prognostic factor in DEK/CAN-positive AML patients.

In our case, 15 AML prognostic genes including FLT3/ ITD gene were all negative. Although common methylation prognostic genes were negatives, as morphological findings suggested that the granulocyte system was abnormal, we gave one course of standard dose chemotherapy of decitabine combined with IA regimen with informed consent of the patient, the cell morphology indicated complete remission. However, MRD and DEK/CAN fusion gene was still positive. Therefore, after one course of chemotherapy with decitabine combined with mid-dose cytarabine, MRD and DEK/CAN fusion genes were not detected, and the complete remission of molecular biology was achieved. After further intensive chemotherapy with decitabine combined with mid-dose cytarabine, AML was still in complete molecular biology remission for 6 months. Studies have reported that $D E K / C A N$ gene negative is often associated with long-term survival of patients, which may provide a new feasible treatment for patients with DEK/ 
CAN-positive AML.

In conclusion, we have achieved a long-term complete remission of molecular biology in patients with DEK/CANpositive AML via decitabine combined with medium-dose cytarabine. However, single case report and the underlying mechanism of negative transformation of DEK/CAN fusion gene is not clear, which is the limitation associated with this case report. Moreover, we hypothesized that the combination of decitabine and medium-dose cytarabine play an important role in targeting DEK/CAN and it should be verified by the accumulation of clinical cases and basic experiments in the future.

\section{Acknowledgments}

Funding: None.

\section{Footnote}

Reporting Checklist: The authors have completed the CARE Reporting Checklist. Available at http://dx.doi. org/10.21037/apm-19-379

Conflicts of Interest: Both authors have completed the ICMJE uniform disclosure form (available at http://dx.doi. org/10.21037/apm-19-379). The authors have no conflicts of interest to declare.

Etbical Statement: The authors are accountable for all aspects of the work in ensuring that questions related to the accuracy or integrity of any part of the work are appropriately investigated and resolved. Ethical approval was obtained from the Ethics Committee of the Second Affiliated Hospital, Fujian Medical University, China (committee's reference number: 2017-388), in accordance with the ethical guidelines of the 1975 Declaration of Helsinki (as revised in 2013). Written informed consent was obtained from the patient for publication of this manuscript and any accompanying images.

Open Access Statement: This is an Open Access article distributed in accordance with the Creative Commons Attribution-NonCommercial-NoDerivs 4.0 International License (CC BY-NC-ND 4.0), which permits the noncommercial replication and distribution of the article with the strict proviso that no changes or edits are made and the original work is properly cited (including links to both the formal publication through the relevant DOI and the license). See: https://creativecommons.org/licenses/by-nc-nd/4.0/.

\section{References}

1. O'Donnell MR, Tallman MS, Abboud CN, et al. Acute Myeloid Leukemia, Version 3.2017, NCCN Clinical Practice Guidelines in Oncology. J Natl Compr Canc Netw 2017;15:926-57.

2. Grimwade D, Hills RK, Moorman AV, et al. Refinement of cytogenetic classification in acute myeloid leukemia: determination of prognostic significance of rare recurring chromosomal abnormalities among 5876 younger adult patients treated in the United Kingdom Medical Research Council trials. Blood 2010;116:354-65.

3. Sandahl JD, Coenen EA, Forestier E, et al. t(6;9)(p22;q34)/ DEK-NUP214-rearranged pediatric myeloid leukemia: an international study of 62 patients. Haematologica 2014;99:865-72.

4. Slovak ML, Gundacker H, Bloomfield CD, et al. A retrospective study of 69 patients with $\mathrm{t}(6 ; 9)(\mathrm{p} 23 ; \mathrm{q} 34)$ AML emphasizes the need for a prospective, multicenter initiative for rare 'poor prognosis' myeloid malignancies. Leukemia 2006;20:1295-7.

5. Kayser S, Hills RK, Luskin MR, et al. Allogeneic hematopoietic cell transplantation improves outcome of adults with $\mathrm{t}(6 ; 9)$ acute myeloid leukemia: results from an international collaborative study. Haematologica 2020;105:161-9.

6. Arber DA, Orazi A, Hasserjian R, et al. The 2016 revision to the World Health Organization classification of myeloid neoplasms and acute leukemia. Blood 2016;127:2391-405.

7. Bohl SR, Bullinger L, Rücker FG. Epigenetic therapy: azacytidine and decitabine in acute myeloid leukemia. Expert Rev Hematol 2018;11:361-71.

8. Thiede C, Steudel C, Mohr B, et al. Analysis of FLT3-activating mutations in 979 patients with acute myelogenous leukemia: association with $\mathrm{FAB}$ subtypes and identification of subgroups with poor prognosis. Blood 2002;99:4326-35.

9. Tarlock K, Alonzo TA, Moraleda PP, et al. Acute myeloid leukaemia (AML) with $\mathrm{t}(6 ; 9)(\mathrm{p} 23 ; \mathrm{q} 34)$ is associated with poor outcome in childhood AML regardless of FLT3-ITD status: a report from the Children's Oncology Group. Br J Haematol 2014;166:254-59.

Cite this article as: Zhang $\mathrm{X}$, Zhang $\mathrm{X}$. Decitabine combined with medium-dose cytarabine in the treatment of DEK/CANpositive acute myeloid leukemia: a case report. Ann Palliat Med 2021;10(4):4955-4958. doi: 10.21037/apm-19-379 